\title{
A failure to reinforce instrumental behavior by terminating a stimulus that had been paired with shock'
}

\author{
ROBERT C. BOLLES, UNIVERSITY OF WASHINGTON \\ ABIGAIL V. TUTTLE, MCMASTER UNIVERSITY
}

Two groups of rats were trained in a shuttle box to escape shock, one by running and the other by rearing up on the hind legs. All Ss were then required to make the other response to terminate the CS in the absence of shock. Approximately equal reinforcement effects were shown by $S$ for whom the CS had been paired with shock and controls for whom it was novel.

Almost everybody belleves that if a stimulus is paired with shock, it will become aversive, so that its termination can be used to reinforce any operant response in S's repertoire (Miller, 1948; Mowrer \& Lamoreaux, 1946; Skinner, 1953). While we do not really question any of the demonstrations that the just cited writers have advanced to support this popular hypothesis, we do question its generality as a fundamental principle of operant (i.e., instrumental) conditioning.

Mowrer \& Lamoreaux (1946) were able to train rats to jump (or run) to avoid shock and terminate the CS, while running (or jumping) to escape shock. The source of reinforcement for the avoidance response could therefore not have been the escape contingency; it must have been, say Mowrer and Lamoreaux, the reduction in fear pursuant to the termination of the CS. The present study came out of our attempts to replicate the Mowrer and Lamoreaux experiment. We used apparatus like theirs, their procedures, and several modifications of their procedures, but we could get little jumping, and what jumping we did get was not strengthened by making CS termination contingent upon its occurrence. We also could not get simultaneous acquisition of different responses for avoidance $\left(R_{a}\right)$ and escape $\left(\mathbf{R}_{\mathcal{e}}\right)$, so we began to investigate the successive acquisition of different $R_{\mathrm{a}}$ s and $R_{e} s$. That is, we abandoned the avoldance paradigm and turned to the "acquired drive" paradigm.

Subjects

The Ss were 40 female Sprague-Dawleys, about three months old.

Apparatus

The apparatus was a large shuttie box built from the description given by Mowrer and Lamoreaux. However, it was equipped with a Lehigh Valley Electronics grid scrambler, $3 / 8$ in. stainless steel rod flooring, and the US was $1.1 \mathrm{~mA}$ dc. (We tried a variety of US conditions, and found that even those like Mowrer and Lamoreaux's did not significantly increase operant fumping.) The CS was an 80 dB white nolse.

\section{Procedure}

In Phase 1, the training phase, the CS was paired with US for the experimental groups and the US was presented alone for the control groups. For all Ss the US came on after a 30 sec intertrial interval, and had to be escaped by the appropriate $R_{e}$, which was running from one side of the shuttle box to the other for half of the experimental and control $\mathrm{Ss}$, and was rearing up on the hind legs for the other half.

In Phase 2, the testing phase, which followed immediately after the tenth training trial, the US was never presented. All Ss were tested with the presentation of the white noise CS alone. In order to demonstrate the acquisition of a new response, the $20 \mathrm{Ss}$ that had learned the running $R_{e}$ were now required to rear up on their hind legs to terminate the CS. Similarly, the $20 \mathrm{Ss}$ that had learned the rearing $R_{e}$ now had to run to terminate the CS.

During the testing the four main groups were furm ther subdivided such that for half of each group the new response, $R_{a}$ (which was not really an avoidance response since there were no more shocks), led to immediate termination of the CS, while for the other half CS termination was delayed for $10 \mathrm{sec}$ after the occurrence of $R_{a}$.

This procedure was followed for 25 trials, with an intertrial interval of $30 \mathrm{sec}$. The maximum possible CS duration was limited to $120 \mathrm{sec}$. It should be emphasized that since the running response had very Ifttle initial strength, it was necessary for $E$ to shape it by approximation; little shaping was required for the rearing response.

To summarize the design: During testing for the acquisition of $\mathbf{R}_{\mathrm{g}}$, the new response, only one subgroup should be expected to learn, namely, that subgroup which had the CS previously paired with the US, and which also had Immediate termination of the CS contingent on $\mathbf{R}_{\mathbf{a}}$. The other pseudoconditioning and sensitization control groups should not learn $\mathbf{R}_{\mathbf{a}}$, either because the CS was not aversive, or because its termination was too long delayed to provide effective relnforcement.

Results

The criterion response measure was the occurrence of $R_{\mathrm{a}}$ with a latency less than 10 sec. The median number of such prompt responses made by each group in a block of five trials is indicated in Fig. 1.

It is clear from the data on the right in the figure 


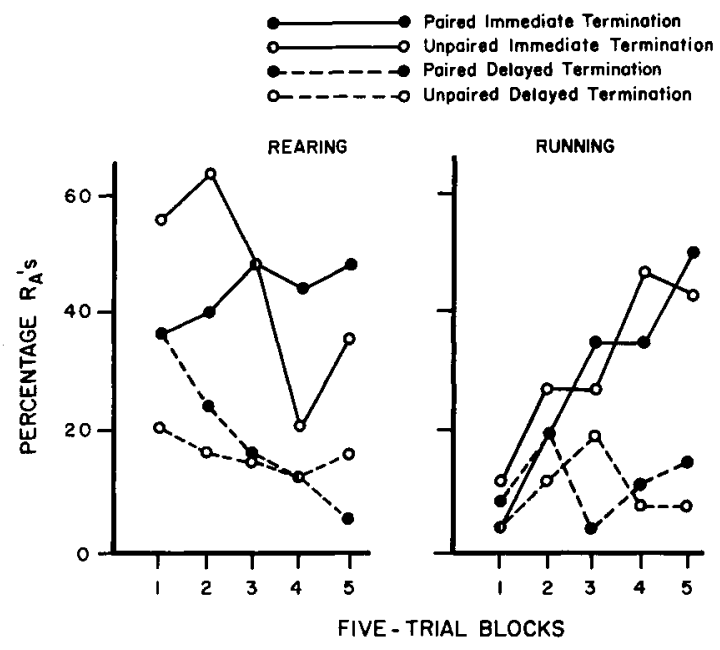

Fig. 1. Acquisition of a new response based on CS termination as a function of immediacy of CS termination and prior CS pairing with shock.

that the initial incidence of the running response was quite low and that it stayed low for all Ss under the delayed CS termination condition. The data on the left show that although the initial incidence of rearing was much higher, there was, again, no strengthening of this $R_{a}$ under the delayed CS termination condition. Thus, the control for sensitization indicates that there was little tendency for the CS to elicit $R_{a}$ in the absence of the CS termination contingency.

With immediate CS termination contingent upon the occurrence of $R_{a}$, there was good acquisition of the running $R_{a}$ and maintenance of the rearing $R_{a}$. The subgroups that were supposed to learn did learn, which, taken by itself, provides good support for the CS termination hypothesis. However, the performance of the pseudoconditioning control subgroup was also quite good. The only acquisition obtained here was found for the running $R_{a}$, and it was acquired every bit as well by Ss for whom the CS had not been previously paired with shock.

The only evidence suggesting a genuine acquired negative reinforcement effect was that CS termination maintained the rearing $R_{a}$ somewhat better if the CS had been previously paired with shock. However, an analysis of variance indicated that the interaction of delay by pairing conditions by trial blocks was not statistically significant $(F=1.36, d f=5 / 80, p>.10)$. Discussion

The present groups are too small to allow a fully quantitative assessment of the situation, but one conclusion seems to be justified: If there is an acquired negative reinforcement effect here, it must be rather puny; it hardly seems potent enough to be the principal reinforcement mechanism in those situations where rapid and durable acquisition of avoidance is found.

Two other factors appear to be important in determining our results. One is the pseudoconditioning effect: Presentation of the CS is evidently as "aversive" to the frightened rat when it is novel as when it has just previously been paired with shock. The need for adequately controlling for this effect has also been demonstrated by Baron (1959) and Smith, McFarland, \& Taylor (1961). Without such a control, the case for the CS termination hypothesis would appear much more convincing.

Finally, we would suggest that some significance can be attached to the fact that the running $R_{a}$ was acquired by our Ss while the rearing $\mathbf{R}_{a}$ was not. It has been suggested elsewhere (Bolles, 1967) that Ss may really only be able to learn $R_{a}$ s wich are in their repertoires of species-specific defense reactions. We would suppose that rearing is not one of the rat's innate defense reactions, but that running is. So too, apparently, is running from a black box to a white box (Allison, Larson, \& Jensen, 1967).

\section{References}

ALLISON, J., LARSON, D., \& JENSEN, D. D. Acquired fear, brightness preference, and one-way shuttlebox performance. Psychon. Sci, $1967,8,269-270$.

BARON, A. Functions of the CS and US in fear conditioning. J. comp. physiol. Psychol, 1959, 52, 591-593.

BOLLES, R. C. Theory of motivation. New York: Harper \& Row, 1967.

MILLER, N. E. Studies in fear as an acquirable drive: I. Fear as motivation and fear-reduction as reinforcement in the learning of new responses. J. exp. Psychol, 1948, 38, 89-101.

MOWRER, O. H., \& LAMOREAUX, R. R. Fear as an intervening variable in avoidance conditioning. J. comp. Psychol, 1946, 39, $29-50$.

SKINNER, B. F. Science and human behavior. New York: Macmillan, 1953.

SMITH, O. A., Jr., McFARLAND, W. L., \& TAYLOR, E. Performance in a shock-avoidance conditioning situation interpreted as pseudoconditioning. J. comp. physiol. Psychol, 1961, 54, 154-157.

\section{Note}

1. Supported by NSF grant GB-5694. 